\title{
Best proximity point theorems for $F$-contractive non-self mappings
}

Mehdi Omidvari, S. M. Vaezpour, and Reza Saadati 


\title{
BEST PROXIMITY POINT THEOREMS FOR $F$-CONTRACTIVE NON-SELF MAPPINGS
}

\author{
M. OMIDVARI, S. M. VAEZPOUR, AND R. SAADATI
}

Received 14 October, 2013

\begin{abstract}
In this article, we prove the existence of a best proximity point for $F$-contractive nonself mappings and state some results in the complete metric spaces. Also we define two kinds of $F$-proximal contraction and extend some best proximity theorems and improve the recent results.
\end{abstract}

2010 Mathematics Subject Classification: 46N40; 47H10; 54H25; $46 \mathrm{~T} 99$

Keywords: metric space, best proximity point, fixed point, $F$-contractive non-self mapping, $F$ proximal contraction

\section{INTRODUCTION}

Let us assume that $A, B$ be two nonempty subsets of a metric space $(X, d)$ and $T: A \longrightarrow B$. Clearly $T(A) \cap A \neq \varnothing$ is a necessary condition for the existence of a fixed point of $T$. Now if $T(A) \cap A=\varnothing$ then to find an element $x \in A$ such that $d(x, T x)=d(A, B)$ which called best proximity point is the idea of best proximity point theorems. In the other words, we determine an approximate solution $x$ such that the error of equation $d(x, T x)=0$ is minimum. Several authors such as Pro1la [2], Reich [4], Sehgal and Singh [6,7], Vertivel, Veermani and Bhattacharyya [8] and others[1] generalized and extended the best proximity point theorems in many directions. In 2011, Sadiq Basha [5] stated the best proximity points theorems for proximal contractions. On the other hand, Wardowski [9] introduced a new type of contraction which called $F$-contraction and proved a fixed point result in complete metric spaces. In this paper, by using Wardowski's contraction, we prove the existence of a best proximity point. Moreover we define $F$-proximal contractions of the first and second kind and establish the best proximity point theorems in spire of Wardowski's contraction.

\section{PRELIMINARY}

Let $A, B$ be two nonempty subsets of a metric space $X$. The following notations will be used throughout this paper: 


$$
\begin{aligned}
& d(y, A):=\inf \{d(x, y): x \in A\}, \\
& d(A, B):=\inf \{d(x, y): x \in A \text { and } y \in B\}, \\
& A_{0}:=\{x \in A: d(x, y)=d(A, B) \text { for some } y \in B\}, \\
& B_{0}:=\{y \in B: d(x, y)=d(A, B) \text { for some } x \in A\} .
\end{aligned}
$$

We recall that $x \in A$ is a best proximity point of the mapping $T: A \longrightarrow B$ if $d(x, T x)=d(A, B)$. It can be observed that a best proximity reduces to a fixed point if the underlying mapping is a self-mapping.

Definition 1 ([3]). Let $(A, B)$ be a pair of nonempty subsets of a metric space $X$ with $A \neq \varnothing$. Then the pair $(A, B)$ is said to have the P-property if and only if

$$
\left.\begin{array}{l}
d\left(x_{1}, y_{1}\right)=d(A, B) \\
d\left(x_{2}, y_{2}\right)=d(A, B)
\end{array}\right\} \Longrightarrow d\left(x_{1}, x_{2}\right)=d\left(y_{1}, y_{2}\right)
$$

where $x_{1}, x_{2} \in A_{0}$ and $y_{1}, y_{2} \in B_{0}$.

It is clear that, for any nonempty subset $A$ of $X$, the pair $(A, A)$ has the P-property.

Definition 2 ([5]). $A$ is said to be approximatively compact with respect to $B$ if every sequence $\left\{x_{n}\right\}$ of $A$ satisfying the condition that $d\left(y, x_{n}\right) \longrightarrow d(y, A)$ for some $y$ in $B$ has a convergent subsequence.

It is easy to see that every set is approximatively compact with respect to itself.

Definition 3 ([5]). Given $T: A \longrightarrow B$ and an isometry $g: A \longrightarrow A$, the mapping $T$ is said to preserve isometric distance with respect to $g$ if

$$
d\left(T g x_{1}, T g x_{2}\right)=d\left(T x_{1}, T x_{2}\right)
$$

for all $x_{1}$ and $x_{2}$ in $A$.

Recently Wardowski [9] defined the following contraction which was called $F$-contraction.

Definition 4. Let $F: \mathbb{R}_{+} \longrightarrow \mathbb{R}$ be a mapping satisfying:

(F1) $F$ is strictly increasing, i.e. for all $a, b \in \mathbb{R}_{+}$such that $\alpha<\beta \Longrightarrow F(\alpha)<F(\beta)$;

(F2) For each sequence $\left\{\alpha_{n}\right\}_{n \in \mathbb{N}}$ of positive numbers $\lim _{n \rightarrow \infty} \alpha_{n}=0$ if and only if $\lim _{n \rightarrow \infty} F\left(\alpha_{n}\right)=-\infty$;

(F3) There exists $k \in(0,1)$ such that $\lim _{\alpha \rightarrow 0^{+}} \alpha^{k} F(\alpha)=0$.

A mapping $T: X \longrightarrow X$ is said to be an $F$-contraction if there exists $\tau>0$ such that

$$
\text { For all } x, y \in X,(d(T x, T y))>0 \Longrightarrow \tau+F(d(T x, T y)) \leq F(d(x, y)) \text {. }
$$


Now, we consider the mapping $F$ in the different types, and we obtain the variety of contractions.

Example 1 ([9]). Let $F: \mathbb{R}_{+} \longrightarrow \mathbb{R}$ be given by the formula $F(\alpha)=\ln \alpha$. It is clear that $\mathrm{F}$ satisfies the (F1)-(F3) ((F3) for any $k \in(0,1))$ conditions of Definition 4. Each mapping $T: X \longrightarrow X$ satisfying (2.1) is an $F$-contraction such that

$$
d(T x, T y) \leq e^{-\tau} d(x, y), \text { for all } x, y \in X, T x \neq T y .
$$

It is clear that for $x, y \in X$ such that $T x=T y$ the inequality $d(T x, T y) \leq e^{-\tau} d(x, y)$ also holds, i.e. $T$ is a Banach contraction.

\section{MAin Results}

Now, let us state our main result.

Theorem 1. Let $A$ and $B$ be non-empty, closed subsets of a complete metric space $X$ such that $A_{0}$ is nonempty. Let $T: A \longrightarrow B$ be an $F$-contraction non-self mapping such that $T\left(A_{0}\right) \subseteq B_{0}$. Assume that the pair $(A, B)$ has the P-property. Then there exists a unique $x^{*}$ in $A$ such that $d\left(x^{*}, T x^{*}\right)=d(A, B)$.

Proof. Choose $x_{0} \in A_{0}$. Since $T x_{0} \in T\left(A_{0}\right) \subseteq B_{0}$, there exists $x_{1} \in A_{0}$ such that $d\left(x_{1}, T x_{0}\right)=d(A, B)$. Again, since $T x_{1} \in T\left(A_{0}\right) \subseteq B_{0}$, there exists $x_{2} \in A_{0}$ such that $d\left(x_{2}, T x_{1}\right)=d(A, B)$. Continuing this process, we can find a sequence $\left\{x_{n}\right\}$ in $A_{0}$ such that

$$
d\left(x_{n+1}, T x_{n}\right)=d(A, B), \quad \text { for all } n \in \mathbb{N} .
$$

$(A, B)$ satisfies the P-property, therefore from (3.1) we obtain

$$
d\left(x_{n}, x_{n+1}\right)=d\left(T x_{n-1}, T x_{n}\right), \quad \text { for all } n \in \mathbb{N} .
$$

We will prove that the sequence $\left\{x_{n}\right\}$ is convergent in $A_{0}$. If there exists $n_{0} \in \mathbb{N}$ such that $d\left(T x_{n_{0}-1}, T x_{n_{0}}\right)=0$, then by (3.2) we have $d\left(x_{n_{0}}, x_{n_{0}+1}\right)=0$ that implies $x_{n_{0}}=x_{n_{0}+1}$. Therefore

$$
T x_{n_{0}}=T x_{n_{0}+1} \Longrightarrow d\left(T x_{n_{0}}, T x_{n_{0}+1}\right)=0
$$

From (3.2) and (3.3) we receive that

$$
d\left(x_{n_{0}+2}, x_{n_{0}+1}\right)=d\left(T x_{n_{0}+1}, T x_{n_{0}}\right)=0 \Longrightarrow x_{n_{0}+2}=x_{n_{0}+1}
$$

Therefore $x_{n}=x_{n_{0}}$, for all $n \geq n_{0}$ and $\left\{x_{n}\right\}$ is convergent in $A_{0}$.

Now let $d\left(T x_{n-1}, T x_{n}\right) \neq 0$, for all $n \in \mathbb{N}$. $T$ is a $F$-contraction and (3.2) holds, hence for any positive integer $n$ we have

$\tau+F\left(d\left(T x_{n}, T x_{n-1}\right)\right) \leq F\left(d\left(x_{n}, x_{n-1}\right)\right)$ 
$\Longrightarrow F\left(d\left(x_{n+1}, x_{n}\right)\right) \leq F\left(d\left(x_{n}, x_{n-1}\right)\right)-\tau$

$\vdots$

$$
\leq F\left(d\left(x_{1}, x_{0}\right)\right)-n \tau
$$

Put $\beta_{n}:=d\left(x_{n+1}, x_{n}\right)$.

From (3.4), we obtain $\lim _{n \rightarrow \infty} F\left(\beta_{n}\right)=-\infty$ that together with (F2) gives

$$
\lim _{n \rightarrow \infty} \beta_{n}=0
$$

Also from $(F 3)$ we have

$$
\exists k \in(0,1) \text { such that } \beta_{n}^{k} F\left(\beta_{n}\right)=0
$$

By (3.3), the following holds for all $n \in \mathbb{N}$ :

$$
F\left(\beta_{n}\right)-F\left(\beta_{0}\right) \leq-n \tau .
$$

Therefore

$$
\beta_{n}^{k} F\left(\beta_{n}\right)-\beta_{n}^{k} F\left(\beta_{0}\right) \leq-n \beta_{n}^{k} \tau \leq 0 .
$$

Letting $k \rightarrow \infty$ in the above inequality and using (3.5),(3.6), we obtain

$$
\lim _{n \rightarrow \infty} n \beta_{n}^{k}=0 .
$$

Hence there exists $n_{1} \in \mathbb{N}$ such that $n \beta_{n}^{k} \leq 1$ for all $n \geq n_{1}$. Therefore for any $n \geq n_{1}$,

$$
\beta_{n} \leq \frac{1}{n^{\frac{1}{k}}} .
$$

This means that series $\sum_{i=1}^{\infty} \beta_{i}$ is convergent.

Now let $m \geq n \geq n_{1}$. By the triangular inequality and (3.7), we have

$$
d\left(x_{m}, x_{n}\right) \leq \beta_{m-1}+\beta_{m-2}+\ldots+\beta_{n} \leq \sum_{i=n}^{\infty} \beta_{i} .
$$

Therefore $\left\{x_{n}\right\}$ is a Cauchy sequence in $A$. Since $(X, d)$ is complete and $A$ is a closed subset of $X$, there exist $x^{*} \in A$ such that

$$
\lim _{n \rightarrow \infty} x_{n}=x^{*}
$$

Since $T$ is continuous, we have $T x_{n} \longrightarrow T x^{*}$. Hence continuity of the metric function $d$ which implies that $d\left(x_{n+1}, T x_{n}\right) \longrightarrow d\left(x^{*}, T x^{*}\right)$. From $(3.1), d\left(x^{*}, T x^{*}\right)=$ $d(A, B)$. So we show that $x^{*}$ is a best proximity of $T$.

The uniqueness of the best proximity point follows from the condition that $T$ is $F$ contraction. That is, suppose that

$$
x_{1}, x_{2} \in A \text { such that } x_{1} \neq x_{2} \text { and } d\left(x_{1}, T x_{1}\right)=d\left(x_{2}, T x_{2}\right)=d(A, B) .
$$

Then by the P-property of $(A, B)$, we have $d\left(x_{1}, x_{2}\right)=d\left(T x_{1}, T x_{2}\right)$. Also 


$$
x_{1} \neq x_{2} \Longrightarrow d\left(x_{1}, x_{2}\right) \neq 0 \text {. }
$$

Therefore

$$
F\left(d\left(x_{1}, x_{2}\right)\right)=F\left(d\left(T x_{1}, T x_{2}\right)\right) \leq F\left(d\left(x_{1}, x_{2}\right)\right)-\tau<F\left(d\left(x_{1}, x_{2}\right)\right),
$$

which is a contraction. Hence the best proximity point is unique.

The following result is a special case of Theorem 1, obtained by setting $A=B$.

Corollary 1. Let $(X, d)$ be a complete metric space and A be a nonempty closed subset of $X$. Let $T: A \longrightarrow A$ be a $F$-contractive self-map. Then $T$ has a unique fixed point $x^{*}$ in $A$.

The next result is an immediate consequence of Theorem 1 by taking $F(\alpha)=\ln \alpha$.

Corollary 2 (Banach Contraction Principle). Let $(X, d)$ be a complete metric space and $A$ be a nonempty closed subset of $X$. Let $T: A \longrightarrow A$ be a contractive self-map. Then $T$ has a unique fixed point $x^{*}$ in A.

Let $F$ be the function as in Definition 4, we define the proximal contractions.

Definition 5. A mapping $T: A \longrightarrow B$ is said to be a $F$-proximal contraction of the first kind if there exists a $\tau>0$ such that

$$
\left.\begin{array}{c}
d\left(u_{1}, T x_{1}\right)=d(A, B) \\
d\left(u_{2}, T x_{2}\right)=d(A, B) \\
d\left(u_{1}, u_{2}\right), d\left(x_{1}, x_{2}\right)>0
\end{array}\right\} \Longrightarrow \tau+F\left(d\left(u_{1}, u_{2}\right)\right) \leq F\left(d\left(x_{1}, x_{2}\right)\right)
$$

where $u_{1}, u_{2}, x_{1}, x_{2} \in A$.

Remark 1. If $T: A \longrightarrow B$ is a $F$-proximal contraction of the first kind and $(A, B)$ has the P-property then $T$ is a $F$-contractive non-self mapping.

Definition 6. A mapping $T: A \longrightarrow B$ is said to be a $F$-proximal contraction of the second kind if there exists a $\tau>0$ such that

$$
\left.\begin{array}{c}
d\left(u_{1}, T x_{1}\right)=d(A, B) \\
d\left(u_{2}, T x_{2}\right)=d(A, B) \\
d\left(T u_{1}, T u_{2}\right), d\left(T x_{1}, T x_{2}\right)>0
\end{array}\right\} \Longrightarrow \tau+F\left(d\left(T u_{1}, T u_{2}\right)\right) \leq F\left(d\left(T x_{1}, T x_{2}\right)\right)
$$

The following theorem is a best proximity point theorem for non-self $F$-proximal contraction of the first kind.

Theorem 2. Let $A$ and $B$ be non-empty, closed subsets of a complete metric space $X$ such that $A_{0}$ is non-empty. Let $T: A \longrightarrow B$ and $g: A \longrightarrow A$ satisfy the following conditions:

(a) $T$ is a continuous $F$-proximal contraction of the first kind.

(b) $g$ is an isometry.

(c) $T\left(A_{0}\right) \subseteq B_{0}$. 
(d) $A_{0} \subseteq g\left(A_{0}\right)$.

Then, there exists a unique element $x \in A$ such that

$$
d(g x, T x)=d(A, B) .
$$

Proof. Choose $x_{0} \in A_{0}$. Since $T x_{0} \in T\left(A_{0}\right) \subseteq B_{0}$ and $A_{0} \subseteq g\left(A_{0}\right)$, there exists $x_{1} \in A_{0}$ such that $d\left(g x_{1}, T x_{0}\right)=d(A, B)$. If $x_{0}=x_{1}$ then put $x_{n}:=x_{1}$ for all $n \geq 2$. Also, since $T x_{1} \in T\left(A_{0}\right) \subseteq B_{0}$ and $A_{0} \subseteq g\left(A_{0}\right)$, there exists $x_{2} \in A_{0}$ such that $d\left(g x_{2}, T x_{1}\right)=d(A, B)$. If $x_{1}=x_{2}$ then put $x_{n}:=x_{2}$ for all $n \geq 3$. Continuing this process, we can find a sequence $\left\{x_{n}\right\}$ in $A_{0}$ such that

$$
d\left(g x_{n+1}, T x_{n}\right)=d(A, B), \text { for all } n \in \mathbb{N} .
$$

We will prove the convergence of the sequence $\left\{x_{n}\right\}$ in $A$. If there exists $n_{0} \in \mathbb{N}$ such that $d\left(g x_{n_{0}}, g x_{n_{0}+1}\right)=0$ then it is clear that the sequence $\left\{x_{n}\right\}$ is convergent. Hence let $d\left(g x_{n}, g x_{n+1}\right) \neq 0$, for all $n \in \mathbb{N}$. $T$ is a $F$-proximal contraction of the first kind and (3.8) holds, hence for any positive integer $n$ we have

$$
\begin{aligned}
& \tau+F\left(d\left(g x_{n}, g x_{n+1}\right)\right) \leq F\left(d\left(x_{n-1}, x_{n}\right)\right) \\
& \Longrightarrow F\left(d\left(x_{n}, x_{n+1}\right)\right) \leq F\left(d\left(x_{n-1}, x_{n}\right)\right)-\tau \\
& \vdots \quad \leq F\left(d\left(x_{0}, x_{1}\right)\right)-n \tau .
\end{aligned}
$$

Similarly as the process in the proof of Theorem $1,\left\{x_{n}\right\}$ is a Cauchy sequence in $A$. Since $X$ is complete metric space and $A$ is closed subset of $X$, there exists $x \in A$ such that $\lim _{n \rightarrow \infty} x_{n}=x$.

Since, $T, g$ and $d$ are continuous, therefore with letting $n \longrightarrow \infty$ in (3.8), we obtain

$$
d(g x, T x)=d(A, B) .
$$

Now, $x^{*}$ be in $A$ such that

$$
d\left(g x^{*}, T x^{*}\right)=d(A, B) .
$$

We show that $x=x^{*}$. Suppose to the contrary, that $x \neq x^{*}$. Hence $d\left(x, x^{*}\right) \neq 0$. Since $T$ is a $F$-proximal contraction of the first kind and $g$ is an isometry,

$$
F\left(d\left(x, x^{*}\right)\right)=F\left(d\left(g x, g x^{*}\right)\right) \leq F\left(d\left(x, x^{*}\right)\right)-\tau<F\left(d\left(x, x^{*}\right)\right),
$$

which is a contraction. Therefore $x=x^{*}$ and this completes the proof of theorem.

The following result is a special case of Theorem 2, if $g$ is the identity mapping.

Corollary 3. Let $A$ and $B$ be non-empty, closed subsets of a complete metric space $X$ such that $A$ is approximatively compact with respect to $B$. Further, suppose that $A_{0}$ is non-empty. Let $T: A \longrightarrow B$ satisfies the following conditions: 
(a) $T$ is a continuous $F$-proximal contraction of the first kind.

(b) $T\left(A_{0}\right) \subseteq B_{0}$.

Then $T$ has a unique best proximity point in $A$.

The following theorem is a best proximity point theorem for non-self $F$-proximal contraction of the second kind.

Theorem 3. Let $A$ and $B$ be non-empty, closed subsets of a complete metric space $X$ such that $A$ is approximatively compact with respect to $B$. Further, suppose that $A_{0}$ is non-empty. Let $T: A \longrightarrow B$ and $g: A \longrightarrow A$ satisfy the following conditions:

(a) $T$ is a continuous $F$-proximal contraction of the second kind.

(b) $g$ is an isometry.

(c) $T\left(A_{0}\right) \subseteq B_{0}$.

(d) $A_{0} \subseteq g\left(A_{0}\right)$.

(e) $T$ preserves isometric distance with respect to $g$.

Then, there exists an element $x \in A$ such that

$$
d(g x, T x)=d(A, B) .
$$

Moreover, if $x^{*}$ is another element of $A$ such that $d\left(g x^{*}, T x^{*}\right)=d(A, B)$ then $T x=$ $T x^{*}$.

Proof. Choose $x_{0} \in A_{0}$. Since $T x_{0} \in T\left(A_{0}\right) \subseteq B_{0}$ and $A_{0} \subseteq g\left(A_{0}\right)$, there exists $x_{1} \in A_{0}$ such that $d\left(g x_{1}, T x_{0}\right)=d(A, B)$. If $T x_{0}=T x_{1}$ then put $x_{n}:=x_{1}$ for all $n \geq 2$. Otherwise again since $T x_{1} \in T\left(A_{0}\right) \subseteq B_{0}$ and $A_{0} \subseteq g\left(A_{0}\right)$, there exists $x_{2} \in \bar{A}_{0}$ such that $d\left(g x_{2}, T x_{1}\right)=d(A, B)$. If $\left.T x_{1}=T x_{2}\right)$ then put $x_{n}:=x_{2}$ for all $n \geq 3$. Continuing this process, we can find a sequence $\left\{x_{n}\right\}$ in $A_{0}$ such that

$$
d\left(g x_{n+1}, T x_{n}\right)=d(A, B), \quad \text { for all } n \in \mathbb{N} .
$$

We will prove the convergence of the sequence $\left\{T x_{n}\right\}$ in $B$. If there exists $n_{0} \in \mathbb{N}$ such that $d\left(T g x_{n_{0}}, T g x_{n_{0}+1}\right)=0$ then it is clear that the sequence $\left\{T x_{n}\right\}$ is convergent. Hence let $d\left(\operatorname{Tg} x_{n}, \operatorname{Tg} x_{n+1}\right) \neq 0$, for all $n \in \mathbb{N}$. $T$ is a $F$-proximal contraction of the second kind, $T$ preserves isometric distance with respect to $g$ and (3.10) holds, hence for any positive integer $n$ we have

$$
\begin{aligned}
\tau+F\left(d\left(T g x_{n}, T g x_{n+1}\right)\right) & \leq F\left(d\left(T x_{n-1}, T x_{n}\right)\right) \\
\Longrightarrow F\left(d\left(T x_{n}, T x_{n+1}\right)\right) \leq & F\left(d\left(T x_{n-1}, T x_{n}\right)\right)-\tau \\
\vdots & \leq F\left(d\left(T x_{0}, T x_{1}\right)\right)-n \tau .
\end{aligned}
$$

Similarly as the process in the proof of Theorem 1, we receive that $\left\{T x_{n}\right\}$ is a Cauchy sequence in $B$. Since $X$ is complete metric space and $B$ is closed subset of $X$, there exists $y \in B$ such that $\lim _{n \rightarrow \infty} T x_{n}=y$.

By the triangular inequality, we have, 


$$
\begin{aligned}
d(y, A) \leq d\left(y, g x_{n}\right) & \leq d\left(y, T x_{n-1}\right)+d\left(T x_{n-1}, g x_{n}\right) \\
= & d\left(y, T x_{n-1}\right)+d(A, B) \\
\leq & \left(y, T x_{n-1}\right)+d(y, A)
\end{aligned}
$$

Letting $k \longrightarrow \infty$ in the above inequality, we obtain

$$
\lim _{n \rightarrow \infty} d\left(y, g x_{n}\right)=d(y, A) .
$$

Since $A$ is approximatively compact with respect to $B$, there exists a subsequence $\left\{g x_{n_{k}}\right\}$ of $\left\{g x_{n}\right\}$ such that converging to some $z \in A$. Therefore

$$
d(z, y)=\lim _{k \rightarrow \infty} d\left(g x_{n_{k}}, T x_{n_{k}-1}\right)=d(A, B) .
$$

This implies that $z \in A_{0}$. Since $A_{0} \subseteq g\left(A_{0}\right)$, there exists $x \in A_{0}$ such that $z=g x$. As $\lim _{n \rightarrow \infty} g\left(x_{n_{k}}\right)=g(x)$ and $g$ is an isometry, we have

$$
\lim _{n \rightarrow \infty} x_{n_{k}}=x .
$$

$T$ is continuous and $\left\{T x_{n}\right\}$ is convergent to $y$, Therefore

$$
\lim _{n \rightarrow \infty} T x_{n_{k}}=T x=y .
$$

Thus, it follows that

$$
d(g x, T x)=\lim _{n \rightarrow \infty} d\left(g x_{n_{k}}, T x_{n_{k}}\right)=d(A, B) .
$$

Now let $x^{*}$ be another element in $A$ such that

$$
d\left(g x^{*}, T x^{*}\right)=d(A, B) .
$$

We will show that $T x=T x^{*}$. Suppose to the contrary, that $T x \neq T x^{*}$. Hence $d\left(T x, T x^{*}\right) \neq 0$. Since $T$ preserves isometric distance with respect to $g$ and $T$ is a $F$-proximal contraction of the second kind,

$$
F\left(d\left(T x, T x^{*}\right)\right)=F\left(d\left(\operatorname{Tg} x, T g x^{*}\right)\right) \leq F\left(d\left(T x, T x^{*}\right)\right)-\tau<F\left(d\left(T x, T x^{*}\right)\right),
$$

which is a contraction. Therefore $T x=T x^{*}$.

The next result is an immediate consequence of the Theorem 3, if $g$ is the identity mapping.

Corollary 4. Let $A$ and $B$ be non-empty, closed subsets of a complete metric space $X$ such that $A$ is approximatively compact with respect to $B$. Further, suppose that $A_{0}$ is non-empty. Let $T: A \longrightarrow B$ satisfies the following conditions:

(a) $T$ is a continuous $F$-proximal contraction of the second kind.

(b) $T\left(A_{0}\right) \subseteq B_{0}$.

Then, $T$ has a best proximity point in A. Moreover, if $x^{*}$ is another best proximity point of $T$ then $T x=T x^{*}$. 


\section{ACKNOWLEDGMENTS}

The authors would like to thank referee for giving useful comments and suggestions for the improvement of this paper.

\section{REFERENCES}

[1] M. R. Haddadi, "Best proximity point iteration for nonexpensive mapping in banach spaces," $J$. Nonlinear Sci. Appl., vol. 7, no. 2, pp. 126-130, 2014.

[2] J. B. Prolla, "Fixed-point theorems for set-valued mappings and existence of best approximants," Numer. Funct. Anal. Optim., vol. 5, no. 4, pp. 449-455, 1982-1983.

[3] V. S. Raj, "A best proximity point theorem for weakly contractive non-self-mappings," Nonlinear Anal., vol. 74, no. 11, pp. 4804-4808, 2011.

[4] S. Reich, "Approximate selections, best approximations, fixed points and invariant sets," J. Math. Anal. Appl., vol. 62, no. 1, pp. 104-113, 1978.

[5] S. Sadiq Basha, "Best proximity point theorems," J. Approx. Theory, vol. 163, no. 11, pp. 1772$1781,2011$.

[6] V. M. Sehgal and S. P. Singh, "A generalization to multifunctions of fan's best approximation theorem," Proc. Amer. Math. Soc., vol. 102, no. 3, pp. 534-537, 1988.

[7] V. M. Sehgal and S. P. Singh, "A theorem on best approximations," Numer. Funct. Anal. Optim., vol. 10, no. 1-2, pp. 181-184, 1989.

[8] V. Vetrivel, P. Veeramani, and P. Bhattacharyya, "Some extensions of fan's best approximation theorem," Numer. Funct. Anal. Optim., vol. 13, no. 3-4, pp. 397-402, 1992.

[9] D. Wardowski, "Fixed points of a new type of contractive mappings in complete metric spaces," Fixed Point Theory Appl., vol. 2012, no. 94, p. 6, 2012.

\section{Authors' addresses}

\section{Omidvari}

Department of Mathematics, Science and Research Branch, Islamic Azad University(IAU), Tehran, Iran

E-mail address: mehdi.omidvariegmail.com

\section{S. M. Vaezpour}

Department of Mathematics and Computer Science, Amirkabir University of Technology, Hafez Ave., P. O. Box 15914, Tehran, Iran

E-mail address: vaez@aut.ac.ir

R. Saadati

Department of Mathematics, Iran University of Science and Technology, Tehran, Iran

E-mail address: rsaadati@iust.ac.ir 